\title{
Occurrence, distribution and potential affecting factors of antibiotics in sewage sludge of wastewater treatment plants in China
}

\author{
Wenhui Li ${ }^{\text {a }}$, Yali Shi ${ }^{\text {a,* }}$, Lihong Gao ${ }^{\text {a,b }}$, Jiemin Liu ${ }^{\text {b }}$, Yaqi Cai ${ }^{\text {a }}$ \\ a State Key Laboratory of Environmental Chemistry and Ecotoxicology, Research Center for Eco-Environmental Science, Chinese Academy of Sciences, Beijing 100085, China \\ b School of Chemistry and Biological Engineering, University of Science and Technology Beijing, University of Science and Technology Beijing, Beijing 100083, China
}

\section{H I G H L I G H T S}

- High level of quinolones in sludge indicated that antibiotics widely existed in China.

- Antibiotic levels in sewage sludge depend on wastewater characteristics.

- TOC could affect the sludge adsorption capability to the antibiotics to some extent.

- Antibiotic levels in sewage sludge increased with longer solid retention time.

\section{A R T I C L E I N F O}

\section{Article history}

Received 17 September 2012

Received in revised form 4 December 2012

Accepted 18 December 2012

Available online 20 January 2013

\section{Keywords:}

Antibiotics

Quinolones

Sulfonamides

Macrolides

Wastewater treatment plant

Sewage sludge

\begin{abstract}
A B S T R A C T
The occurrence and distribution of eight quinolones, nine sulfonamides, and five macrolides were investigated in sewage sludge from 45 wastewater treatment plants in 23 cities in China. Among all the antibiotics considered, quinolones were the dominant antibiotics detected in all samples [total concentrations up to $8905 \mu \mathrm{g} / \mathrm{kg}$, dry weight (dw)], followed by macrolides $(85.1 \mu \mathrm{g} / \mathrm{kg}, \mathrm{dw})$, and sulfonamides $(22.7 \mu \mathrm{g} / \mathrm{kg}$, $\mathrm{dw}$ ). High concentrations of quinolones in sewage sludge indicated that antibiotics are widely used and extensive pollutants in China. Significant differences were observed for the total concentrations of antibiotics in sludge samples among the 45 WWTPs. To evaluate the potential factors affecting the antibiotic levels in sewage sludge, wastewater and sludge characteristics, as well as the operational conditions and treatment techniques in WWTPs were investigated. The results indicated that the antibiotic levels in sewage sludge depend to a great extent on wastewater characteristics. Significant correlation between total organic carbon (TOC) and total concentrations of antibiotics was also found in studied WWTPs, indicating that TOC could affect the sludge adsorption capability to the antibiotics to some extent. Moreover, the relation between treatment techniques and the total concentrations of antibiotics in sludge showed that antibiotic levels in sludge increased with longer solid retention time.
\end{abstract}

(c) 2012 Elsevier B.V. All rights reserved.

\section{Introduction}

Antibiotics, an emerging group of environmental contaminant, are wildly used as human medicine and veterinary drugs to prevent or treat infective diseases, and as growth promoter in livestock farming, aquaculture and agriculture (Gao et al., 2012; Zuccato et al., 2010). Many antibiotics administered to humans and animals cannot be completely absorbed or metabolized in the body, and most of them were directly discharged into the sewage system through excretion (Bendz et al., 2005; Carballa et al., 2005).

Municipal wastewater systems are a major pathway for the disposal of antibiotics, and the concentrations measured in wastewater treatment plant (WWTP) influents can reflect the levels of antibiotics in its serving region (Al-Rifai et al., 2011; Jelić et al., 2009). In WWTPs,

\footnotetext{
* Corresponding author. Tel./fax: + 861062849182.

E-mail address: shiyali@rcees.ac.cn (Y. Shi).
}

antibiotics were removed mainly through sorption and biodegradation by the activated sludge (Hyland et al., 2012; Jelic et al., 2011; Maeng et al., 2011; Yang et al., 2012). For some antibiotics, especially hydrophobic antibiotics, with their limited mobility and low biodegradation in the sludge, they are prone to adsorb onto sewage sludge and more stable than those in wastewater (Baquero et al., 2008; Cruz Moreno-Bondi et al., 2009; Zhou et al., 2009). Several studies have reported that many antibiotics in wastewater were considerably eliminated by sorption and transported to sewage sludge during sewage treatment (Batt et al., 2007; Beausse, 2004; Escher et al., 2011; Hörsing et al., 2011), indicating that sludge can serve as an important reservoir of antibiotics. Therefore, concentrations of antibiotics in sewage sludge can give an important indication on their pollution levels to some extent. In addition, it has been recognized that the disposal of sludge, such as agricultural application and landfill, can potentially release the antibiotics into the environment. Peng et al. (2011) have reported that about $22,800 \mathrm{~kg}$ fluoroquinolones 
may enter the terrestrial environment via disposal of sewage sludge in Guangzhou in 2007. Once they enter the environment, antibiotics may pose potential risks to human and health ecosystems (Sapkota et al., 2008; Wu et al., 2010). Thus, the occurrence and fate of antibiotics in sewage sludge should be emphasized.

So far, extensive studies have been conducted on the occurrence of antibiotics in the influent and effluent of WWTPs (Gulkowska et al., 2008; Karthikeyan and Meyer, 2006; Zorita et al., 2009), while only limited information was available on the occurrence and distribution patterns of antibiotics in sludge mainly due to its high complex matrix (Jelic et al., 2011; Kümmerer, 2009). It was reported that the concentrations of antibiotics ranged from $\mu \mathrm{g} / \mathrm{kg}$ to a few $\mathrm{mg} / \mathrm{kg}$ in sewage sludge from different countries, such as Estonian (Lillenberg et al., 2009), Italy (Zuccato et al., 2010), Spain (Nieto et al., 2010; Radjenović et al., 2009), Switzerland (Göbel et al., 2005), USA (Kinney et al., 2006), Japan (Okuda et al., 2009) and China (Xu et al., 2007). In China, there are over 30 million tons of sewage sludge (moisture content: $80 \%$ ) generated in 2011, and $75-85 \%$ of them cannot be safely disposed (Zou and Wang, 2012). Moreover, high levels of antibiotics have been found in sewage sludge, in which the concentration was up to several $\mathrm{mg} / \mathrm{kg}$ (Gao et al., 2012). Therefore, antibiotic contamination in sewage sludge has become a severe problem in China, and it is necessary to monitor their concentrations on a large scale. The aim of this study was to investigate the occurrence and distribution of 22 common antibiotics in the sewage sludge in China, and to assess potential factors affecting the antibiotic levels in sewage sludge in 45 WWTPs. We hope that this study would provide useful information to indicate the antibiotic pollution levels in China. As far as we know, this is the first study demonstrating the ubiquitous occurrence of antibiotics in China.

\section{Materials and methods}

\subsection{Standards and reagents}

HPLC-grade methanol and acetonitrile were purchased from Fisher Scientific (Pittsburgh, PA, USA); formic acid (98\%) was purchased from Fluka; ammonium formate (99\%) and ammonium hydroxide (v/v, 50\%) were purchased from Alfa Aesar. All purity water ( $>18.2 \mathrm{M} \Omega . \mathrm{cm}^{-1}$ ) was prepared with Milli-Q Advantage A10 system (Millipore, USA).

Ofloxacin (OFL, 99.9\%), norfloxacin (NOR, 99.9\%), ciprofloxacin (CIP, 99.9\%), sarafloxacin (SAR, 95.0\%), fleroxacin (FLE, 99.5\%), lomefloxacin (LOM, 98.0\%), difloxacin (DIF, 98.0\%), enrofloxacin (ENR, 99.9\%), sulfadiazine (SDZ, 99.7\%), sulfamerazine (SMR, 99.9\%), sulfadimethoxine (SDM, 99.4\%), sulfisoxazole (SIA, 99.0\%), sulfamonomethoxine (SMM, 99.0\%), erythromycin (ERY, 99.1\%), roxithromycin (ROX, 90.0\%), josamycin (JOS, 98.0\%), tylosin (TYL, 82.4\%), and spiramycin (SPI, 88.9\%) were purchased from Sigma-Aldrich (St. Louis, MO, USA). Sulfathiazole (STZ, 99.0\%), sulfapyridine (SPD, 99.0\%), sulfamethoxazole (SMX, 99.0\%), and sulfamethazine (SMZ, 99.0\%) were purchased from KaSei Industry Co., Ltd. (Tokyo, Japan).

The following isotopically labeled compounds were used as surrogates standards $\left(100.0 \mu \mathrm{g} / \mathrm{L}\right.$ in methanol): ofloxacin- $\mathrm{d}_{3}$ $\left(\right.$ OFL- $\left.d_{3}\right)$, norfloxacin- $d_{5}\left(N O R-d_{5}\right)$ and sarafloxacin- $d_{8}\left(S A R-d_{8}\right)$ that were purchased from Sigma-Aldrich (St. Louis, MO, USA); and sulfamethoxazole- $\mathrm{d}_{4}\left(\mathrm{SMX}-\mathrm{d}_{4}\right)$, sulfamethazine- $\mathrm{d}_{4}\left(\mathrm{SMZ}-\mathrm{d}_{4}\right)$, spiramycin I- $\mathrm{d}_{3}$ (SPI I- $\left.\mathrm{d}_{3}\right)$, and erythromycin $-{ }^{13} \mathrm{C}, \mathrm{d}_{3}\left(\right.$ ERY- $\left.-{ }^{13} \mathrm{C}, \mathrm{d}_{3}\right)$ that were purchased from Toronto Research Chemicals (Oakville, ON, Canada).

\subsection{Sample collection}

The sampling map and locations are shown in Fig. 1. A total of 45 sewage sludge samples were collected from different WWTPs in 23 cities in China during the period of October 2010 to March 2011.
Considering the impact of precipitation on the antibiotic concentrations, the sampling campaign was carried out during the dry season to avoid the dilution effects of precipitation. The selected cities cover 13 economically developed provinces in China. Details of each WWTP about treatment technique, sewage sources, treatment capacity, actual daily loads and serving population are supplied in Table S1.

All sludge samples were collected in polyethylene bags. They were centrifuged and immediately freeze-dried after being delivered to the laboratory. The sludge was ground and sieved to smaller than $0.44 \mathrm{~mm}$, and then stored at $-20{ }^{\circ} \mathrm{C}$ until analysis.

\subsection{Sample preparation and analysis}

The total organic carbon (TOC) content was measured as $\mathrm{CO}_{2}$ on acid treated samples with a Solid TOC Analyzer (O.I. Analytical Co., USA). TOC concentrations were calculated by the difference between total carbon and inorganic carbon. Chemical analysis was performed following the EPA method 1694 with some modifications (EPA, 2007). Target antibiotics from sludge samples were extracted with an ASE 350 pressurized liquid extraction (PLE) system (Dionex, Sunnyvale, CA, USA), and then purified using AutoTrace SPE 280 (Dionex, USA) with an Oasis HLB cartridge $\left(6 \mathrm{~cm}^{3}, 200 \mathrm{mg}\right.$; Waters, USA).

A total of $0.1 \mathrm{~g}$ pretreated lyophilized sample was spiked with $20 \mathrm{ng}$ of surrogate standard (ofloxacin- $\mathrm{d}_{3}$, norfloxacin- $\mathrm{d}_{5}$, sarafloxacin- $\mathrm{d}_{8}$, sulfamethoxazole- $\mathrm{d}_{4}$, sulfamethazine- $\mathrm{d}_{4}$, spiramycin $\mathrm{I}-\mathrm{d}_{3}$ and erythromycin- ${ }^{13} \mathrm{C}, \mathrm{d}_{3}$ ) before being thoroughly mixed with $3 \mathrm{~g}$ of EDTA-washed diatomite from Dionex (Sunnyvale, CA, USA). The mixture was placed into a $10-\mathrm{mL}$ stainless steel extraction cell with $100 \%$ methanol as the extracting solvent. The extraction conditions were as follows: extraction temperature, $70^{\circ} \mathrm{C}$; extraction pressure, 10.34 MPa; preheating period, $5 \mathrm{~min}$; static extraction, $10 \mathrm{~min}$; final extraction volume, $60 \mathrm{~mL}$; flush volume, $60 \%$ of the cell volume; nitrogen purge, $100 \mathrm{~s}$; and number of extraction cycles, 2.

After extraction, $25 \mathrm{~mL}$ extract was transferred to a $100-\mathrm{mL}$ round-bottom flask, and then concentrated with an RE-2000 rotary evaporator (Yarong, Shanghai, China) at $37{ }^{\circ} \mathrm{C}$ and $0.08 \mathrm{MPa}$ to a final volume of about $1 \mathrm{~mL}$. The extract was immediately transferred to a $100-\mathrm{mL}$ conical tube and diluted to a final volume of $100 \mathrm{~mL}$ with DI water.

The SPE procedure was performed on an AutoTrace SPE 280 system (Dionex, USA). The HLB cartridges were conditioned with $5 \mathrm{~mL}$ methanol and $5 \mathrm{~mL}$ DI water. The $100-\mathrm{mL}$ diluted extract was passed through the cartridge at a flow rate of $2 \mathrm{~mL} / \mathrm{min}$. After all extracts were loaded, cartridges were washed with $10 \mathrm{~mL}$ DI water, and then dried under a nitrogen stream for 20 min. Finally, the analytes were eluted with $6 \mathrm{~mL}$ of methanol containing 5\% ammonium hydroxide. The eluate was concentrated to $1 \mathrm{~mL}$ under a gentle stream of nitrogen at $35{ }^{\circ} \mathrm{C}$ before being dissolved with $1 \mathrm{~mL}$ of a mixture of methanol/aqueous solution of $0.05 \%$ formic acid (10: $90 \mathrm{v} / \mathrm{v}$ ). Then the extract was centrifuged for $5 \mathrm{~min}$ at $12,000 \mathrm{rpm}$. Finally, the supernatant was filtered through a $0.22-\mu \mathrm{m}$ nylon membrane, and an aliquot ( $15 \mu \mathrm{L}$ ) of the filtered supernatant was injected into the HPLC-ESI MS/MS system for analysis.

\subsection{Quantitation and quality control}

The concentrations were determined by an internal standard method. The calibration curve was prepared within a wide range of concentrations $(0.01-500 \mu \mathrm{g} / \mathrm{L})$ to reveal strong linearity $\left(r^{2}>0.99\right)$. The limits of detections (LODs) and recoveries for sludge are listed in Table S2. LODs were determined as the amounts for which signal-to-noise ratios $(\mathrm{S} / \mathrm{N})$ were higher than 3 .

By measuring the concentrations before and after 1 month's storage in the dark at $-20{ }^{\circ} \mathrm{C}$, most antibiotics have no or small degradation loss, except erythromycin (10.7\%). Field blanks and procedural blanks were analyzed with extraction to control travel contamination 


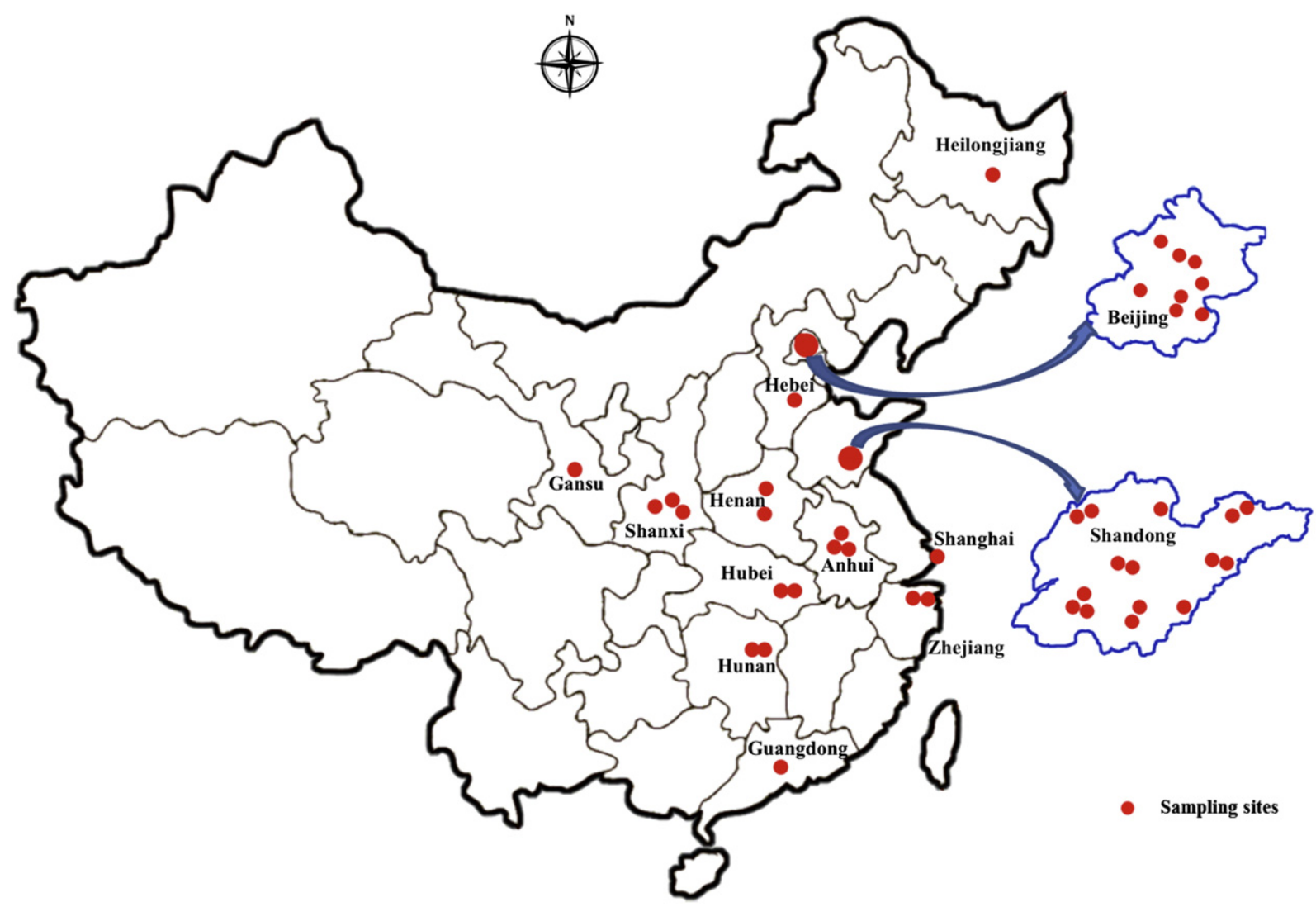

Fig. 1. Sampling locations of municipal sewage sludge samples in China.

and laboratory contamination, and all equipments and containers were rinsed with methanol and water before use to avoid analytical interference and/or cross contamination. A $10 \mu \mathrm{g} / \mathrm{L}$ standard was set as the quality control concentration, which was checked every 10 injections to ensure analysis stability and to verify calibration. The calibration curve was used for quantification only when the quality control standard was within $20 \%$ of its initial value. Detailed information was listed in Table S3 in the Supplementary materials.

\subsection{Statistical analysis}

All statistical analyses were performed with IBM PASW Statistics 20.0 (IBM Corp., 1989-2011). Comparisons of concentrations were performed using Two-Sample Kolmogorov-Smirnov nonparametric tests. It was considered as statistically significant difference when $p<0.05$ for this test. PCA on the analytical data was executed in order to obtain a visual representation of the main characteristics, and the principal components (PCs) were extracted for eigenvalues that were greater than 1 .

\section{Results and discussion}

\subsection{Concentrations of antibiotics in sewage sludge}

The dry-weight-based concentrations of 22 antibiotics in sewage sludge are summarized in Table 1 . The concentrations of individual quinolones, macrolides, and sulfonamides are illustrated by boxand-whisker plots in Fig. 2a, b, and c, respectively. A total of 18 antibiotics, including seven quinolones (NOR, CIP, ENR, FLE, OFL, LOM, and SAR), six sulfonamides (STZ, SMX, SPD, SMZ, SDZ, and SMM), and five macrolides (SPI, JOS, TYL, ROX and ERY), were detectable in the 45 sludge samples. Concentrations of $\sum \mathrm{QNs}, \sum \mathrm{MCs}$ and $\sum \mathrm{SAs}$ ranged from 124 to $29,647 \mu \mathrm{g} / \mathrm{kg}$ [mean $8905 \mu \mathrm{g} / \mathrm{kg}$, dry weight (dw)], from 0.34 to $392.56 \mu \mathrm{g} / \mathrm{kg}$ (mean $85.1 \mu \mathrm{g} / \mathrm{kg}$, dw) and from BDL to $75.6 \mu \mathrm{g} / \mathrm{kg}$ (mean $22.7 \mu \mathrm{g} / \mathrm{kg}$, dw) respectively.

As illustrated in Fig. S1, the sewage sludge samples from 45 WWTPs showed very similar composition profiles of antibiotics, indicating their universal usages and extensive pollution in China. Composition analysis also indicated that the predominant antibiotics in sludge samples were quinolones, which accounted in average for

Table 1

Concentrations of targeted antibiotics in sludge samples $(\mu \mathrm{g} / \mathrm{kg}, \mathrm{dw})$.

\begin{tabular}{llcccc}
\hline Groups & Analytes & Minimum & Maximum & Mean & Frequency (\%) \\
\hline Quinolones & NOR & 75.5 & 21,335 & 5399 & 100 \\
& CIP & 0.00 & 926 & 285 & 97.8 \\
& DIF & 0.00 & 0.00 & 0.00 & 0.00 \\
& ENR & 0.00 & 41.9 & 10.5 & 95.6 \\
& FLE & 0.00 & 1840 & 407 & 97.8 \\
& OFL & 33.9 & 7788 & 2686 & 100 \\
& LOM & 0.00 & 502 & 118 & 97.8 \\
& SAR & 0.00 & 14.6 & 0.87 & 6.67 \\
Sulfonamides & STZ & 0.00 & 0.75 & 0.02 & 2.22 \\
& SMX & 0.00 & 17.0 & 3.90 & 71.1 \\
& SIA & 0.00 & 0.00 & 0.00 & 0.00 \\
& SPD & 0.00 & 47.7 & 8.57 & 91.1 \\
& SDM & 0.00 & 0.00 & 0.00 & 0.00 \\
& SMZ & 0.00 & 11.7 & 0.72 & 64.4 \\
& SDZ & 0.00 & 51.9 & 8.95 & 75.6 \\
& SMR & 0.00 & 0.00 & 0.00 & 0.00 \\
& SMM & 0.00 & 11.1 & 0.58 & 17.8 \\
Macrolides & SPI & 0.00 & 13.3 & 3.64 & 62.2 \\
& JOS & 0.00 & 6.30 & 0.60 & 11.1 \\
& TYL & 0.00 & 33.8 & 0.89 & 6.67 \\
& ROX & 0.00 & 342 & 69.6 & 95.6 \\
& ERY & 0.00 & 55.8 & 10.4 & 97.8 \\
\hline
\end{tabular}



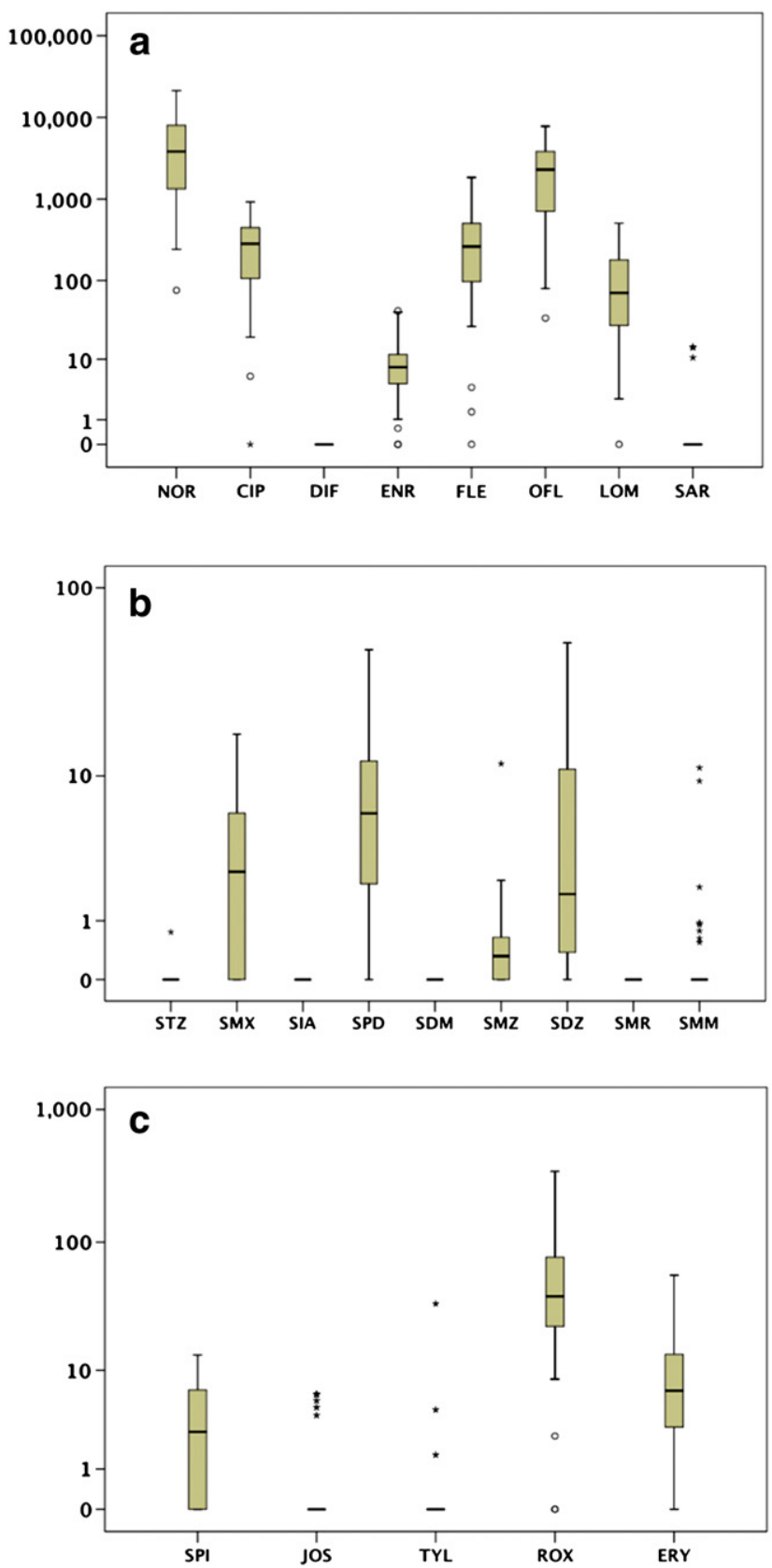

Fig. 2. Box-and-whisker plots of antibiotics in sludge samples collected from 45 WWTPs in China. The horizontal black line in the box represented the median value and the low and upper edges of the box mark, the 25 th and 75 th percentiles. The whiskers extending from the box show the highest and lowest values. " $\star$ "represents extreme values, which were beyond the triplication of the difference between 25th and 75 th percentiles, and singular values are represented by "O", which were beyond the 150 th percentile of the difference between 25 th and 75 th percentiles.

$98.80 \%$ of the total antibiotics. In contrast, the other two groups of antibiotics, macrolides $(0.94 \%)$ and sulfonamides $(0.25 \%)$, contributed little to the total antibiotics. In general, the concentration of antibiotics in sludge mainly depends on the solid-water distribution coefficient (Kd) (Baquero et al., 2008). It has been reported that Kds of quinolones were relatively high (Okuda et al., 2009), which were up to two or three orders of magnitude higher than those of macrolides and sulfonamides (Li et al., 2012). Compared with macrolides and sulfonamides, quinolones showed high persistence in sludge due to their strong adsorption onto sewage sludge by chelating with cations and binding with particulate matter, which delay their degradation
(Cruz Moreno-Bondi et al., 2009; Robinson et al., 2005; Tamtam et al., 2008).

\subsubsection{Quinolones}

NOR (mean $5399 \mu \mathrm{g} / \mathrm{kg}$ ) and OFL (mean $2686 \mu \mathrm{g} / \mathrm{kg}$ ), two quinolones widely used in hospital in China, were detected in all sludge samples. FLE (mean $407 \mu \mathrm{g} / \mathrm{kg}$ ), CIP (mean $285 \mu \mathrm{g} / \mathrm{kg}$ ), LOM (mean $118 \mu \mathrm{g} / \mathrm{kg}$ ) and ENR (mean $10.5 \mu \mathrm{g} / \mathrm{kg}$ ) were also frequently detected in most samples (95.6-97.8\%). It should be noted that, FLE, and LOM, which had not been reported in sludge before, were also detected at relative high levels in the sludge samples in the present study. The mean concentration of SAR was below $1 \mu \mathrm{g} / \mathrm{kg}$, while DIF was not detected in any sludge sample.

The concentrations of quinolones detected in the sludge in this study were comparable to those previously reported in Japan (CIP: mean $243 \mu \mathrm{g} / \mathrm{kg}$ ) (Okuda et al., 2009). However, the concentrations of some quinolones in the sludge were at least ten times higher than those in Hong Kong (OFL: $835 \mu \mathrm{g} / \mathrm{kg}$; NOR: $372 \mu \mathrm{g} / \mathrm{kg}$ ) (Xu et al., 2007), Japan (NOR: $87 \mu \mathrm{g} / \mathrm{kg}$ ) (Okuda et al., 2009), Estonian (OFL: $4-10.9 \mu \mathrm{g} / \mathrm{kg}$; NOR: 20.8-25.0 $\mu \mathrm{g} / \mathrm{kg}$; CIP: $32.8-35.5 \mu \mathrm{g} / \mathrm{kg}$ ) (Lillenberg et al., 2009), Italy (OFL: $3.4 \mu \mathrm{g} / \mathrm{kg}$ ) (Zuccato et al., 2010) and Spain (OFL: $8.4 \mu \mathrm{g} / \mathrm{kg}$ ) (Radjenović et al., 2009), indicating that the levels of quinolone pollution in China were relatively high.

\subsubsection{Macrolides}

The concentrations of macrolides in sludge were much lower than those of quinolones. ROX, ERY and SPI were frequently detected in sludge samples with the mean concentration of $69.6,10.4 \mu \mathrm{g} / \mathrm{kg}$, and $3.64 \mu \mathrm{g} / \mathrm{kg}$, respectively. This may be attributed to their high consumption in China (Chang et al., 2010). As for the other two macrolides, TYL and JOS, showed very rare detection and low concentration in sludge samples.

The concentrations of macrolides detected in the sludge in this study were lower than those previously reported in Hong Kong (ERY: $63 \mu \mathrm{g} / \mathrm{kg}$ ) (Xu et al., 2007), USA (ERY: $41 \mu \mathrm{g} / \mathrm{kg}$ ) (Kinney et al., 2006) and Spain (ERY: $62.5 \mu \mathrm{g} / \mathrm{kg}$; TYL: $1074 \mu \mathrm{g} / \mathrm{kg}$ ) (Radjenović et al., 2009), indicating that the levels of macrolides pollution in this study were relatively low.

\subsubsection{Sulfonamides}

As shown in Table 1, no sulfonamide possessed the mean concentration over $10 \mu \mathrm{g} / \mathrm{kg}$. Similar low concentration of these antibiotics was also reported to be present in sewage sludge samples from various WWTPs in Estonian (Lillenberg et al., 2009), Spain (Nieto et al., 2010), and Japan (Okuda et al., 2009). This may be due to the fact that sulfonamides appeared to have little sorption affinities to sludge, as was evidenced by their low values of Kds (Okuda et al., 2009). In addition, sulfonamides are primarily used for animals (Chang et al., 2010; Malintan and Mohd, 2006), and only a small percentage of them are used for human medicine. Therefore, the concentrations of sulfonamides in sludge were much lower than those of quinolones and macrolides.

\subsection{Comparison of different WWTPs}

The concentrations for total antibiotics in different WWTPs are summarized in Fig. S2. The highest level of total antibiotics $(29,825 \mu \mathrm{g} / \mathrm{kg})$ was found at Xianyang in Shanxi Province, while the lowest level $(125 \mu \mathrm{g} / \mathrm{kg})$ was found at Ningbo in Zhejiang province (Table 2). In general, significant differences were observed for the total concentrations of antibiotics in sludge samples among the 45 WWTPs $(\mathrm{p}<0.05)$.

In order to assess the potential factors affecting the antibiotic levels in sewage sludge, related information, such as characteristics of sewage (domestic, industrial, or combined) and sludge (total organic carbon), and the design and operational conditions of WWTPs 
(treatment technique, treatment capacity, processing volume, and serving population)(Table S3) were investigated.

\subsubsection{Composition of the sewage}

In general, domestic sewage and industrial wastewater were the main sources of WWTPs (Díaz-Cruz et al., 2009; Nieto et al., 2010). Among the 45 WWTPs investigated, 32 WWTPs were fed with mix of domestic sewage and industrial wastewater, 12 WWTPs were fed with domestic sewage, and only one was fed with industrial wastewater taken from an electroplating factory. As shown in Fig. S2, the lowest antibiotic levels in the sludge samples were detected in WWTP NB-3, which was only fed with industrial wastewater. We also found that the antibiotic levels detected in WWTPs fed with combined water (mean $10,162 \mu \mathrm{g} / \mathrm{kg}$ ) were lower than those in WWTPs fed with domestic water (mean $13,788 \mu \mathrm{g} / \mathrm{kg}$ ). Previous studies have reported that domestic sewage contains a vast majority of antibiotics from excretion of human drugs and release of hospital wastes (Ellis, 2006; Xu et al., 2007), which may transport to sewage sludge by sorption during sewage treatment. However, without the direct entry of antibiotics, it is assumed that industrial wastewater (excluding pharmaceutical wastewater) contains little or only a small quantity of antibiotics. As mentioned above, it can be concluded that the concentrations of antibiotics present in sludge samples

Table 2

Concentrations of targeted antibiotics in 45 WWTPs $(\mu \mathrm{g} / \mathrm{kg}, \mathrm{dw})$.

\begin{tabular}{|c|c|c|c|c|c|c|c|}
\hline NO. & Provinces & Cities & WWTPs & QNs & SAs & MCs & Total \\
\hline 1 & Beijing & Beijing & $\mathrm{BJ}-1$ & 989 & 22.0 & 22.0 & 1033 \\
\hline 2 & & & BJ-2 & 4207 & 30.1 & 46.7 & 4284 \\
\hline 3 & & & $\mathrm{BJ}-3$ & 8355 & 44.6 & 208.7 & 8608 \\
\hline 4 & & & BJ-4 & 5112 & 48.2 & 42.4 & 5202 \\
\hline 5 & & & BJ-5 & 10,096 & 58.6 & 40.9 & 10,195 \\
\hline 6 & & & BJ-6 & 8740 & 75.6 & 32.7 & 8848 \\
\hline 7 & & & BJ-7 & 5022 & 34.0 & 39.5 & 5096 \\
\hline 8 & & & BJ-8 & 1780 & 7.70 & 20.7 & 1808 \\
\hline 9 & Shangdong & Dezhou & DZ-1 & 350 & 1.22 & 13.9 & 365 \\
\hline 10 & & & DZ-2 & 1890 & 0.14 & 2.54 & 1893 \\
\hline 11 & & Laiwu & LW-1 & 875 & 1.10 & 10.9 & 887 \\
\hline 12 & & & LW-2 & 2241 & 1.27 & 9.67 & 2252 \\
\hline 13 & & Jining & JN-1 & 2284 & 7.67 & 140.4 & 2432 \\
\hline 14 & & & JN-2 & 1321 & 26.9 & 54.1 & 1402 \\
\hline 15 & & Jining & JN-3 & 1923 & 22.9 & 392.6 & 2339 \\
\hline 16 & & Linyi & LY-1 & 7478 & 16.7 & 46.7 & 7542 \\
\hline 17 & & & LY-2 & 7860 & 9.18 & 27.0 & 7896 \\
\hline 18 & & Qingdao & QD-1 & 10,248 & 14.7 & 37.7 & 10,300 \\
\hline 19 & & & QD-2 & 15,144 & 10.7 & 100.0 & 15,255 \\
\hline 20 & & Yantai & YT-1 & 8431 & 8.04 & 44.1 & 8483 \\
\hline 21 & & & YT-2 & 8332 & 29.6 & 313.5 & 8675 \\
\hline 22 & & Rizhao & $\mathrm{RZ}$ & 9800 & 22.9 & 190.7 & 10,013 \\
\hline 23 & & Dongying & DY & 5633 & 6.95 & 28.5 & 5669 \\
\hline 24 & Shanghai & Shanghai & $\mathrm{SH}$ & 19,703 & 57.1 & 51.0 & 19,811 \\
\hline 25 & Zhejiang & Hangzhou & $\mathrm{HZ}-1$ & 12,300 & 15.2 & 25.8 & 12,341 \\
\hline 26 & & & $\mathrm{HZ}-2$ & 10,701 & 5.54 & 68.1 & 10,775 \\
\hline 27 & & Ningbo & NB-1 & 639 & 0.00 & 5.89 & 645 \\
\hline 28 & & & NB-2 & 3762 & 11.8 & 29.2 & 3803 \\
\hline 29 & & & NB-3 & 124 & 0.00 & 0.34 & 125 \\
\hline 30 & Anhui & Hefei & HF-1 & 17,386 & 31.7 & 57.2 & 17,475 \\
\hline 31 & & & HF-2 & 9060 & 39.3 & 61.7 & 9161 \\
\hline 32 & & & HF-3 & 15,509 & 18.8 & 76.1 & 15,604 \\
\hline 33 & Hebei & Baoding & $\mathrm{BD}$ & 1182 & 2.48 & 95.2 & 1280 \\
\hline 34 & Henan & Xinxiang & $X X$ & 13,683 & 20.0 & 85.6 & 13,788 \\
\hline 35 & & Puyang & PY & 11,444 & 26.6 & 102.6 & 11,573 \\
\hline 36 & Hubei & Wuhan & WH-1 & 5894 & 6.31 & 52.8 & 5953 \\
\hline 37 & & & WH-2 & 8397 & 14.5 & 41.3 & 8453 \\
\hline 38 & Hunan & Changsha & CS-1 & 4209 & 0.63 & 79.4 & 4289 \\
\hline 39 & & & CS-2 & 4717 & 0.39 & 48.3 & 4765 \\
\hline 40 & Guangdong & Zhongshan & ZS & 18,096 & 12.4 & 129.9 & 18,238 \\
\hline 41 & Shanxi & Xianyang & $X Y$ & 29,647 & 55.2 & 123.4 & 29,825 \\
\hline 42 & & Xi'an & $\mathrm{XA}-1$ & 27,043 & 42.0 & 288.0 & 27,373 \\
\hline 43 & & & XA-2 & 20,430 & 27.4 & 105.0 & 20,562 \\
\hline 44 & Gansu & Lanzhou & $\mathrm{LZ}$ & 17,122 & 61.9 & 98.3 & 17,282 \\
\hline 45 & Heilongjiang & Jiamusi & JMS & 21,587 & 73.6 & 339.6 & 22,000 \\
\hline
\end{tabular}

probably associated with the different sources of the wastewater in the studied WWTPs.

\subsubsection{TOC in the sewage sludge}

Total organic carbon is usually considered as one of the most important properties of solid environmental matrices (soil, sediment and sludge), because it may influence other physical, chemical, and biological characteristics. It has been reported that the adsorptions of some antibiotics, such as tetracycline and quinolones, are related to organic carbon content of the soil and sediment (Jia et al., 2012; Pomati et al., 2004; Zhang et al., 2011; Zhou et al., 2011). Therefore, the contents of total organic carbon (TOC, \%) in sludge samples were also investigated to assess the potential influence on the antibiotic levels. As shown in Table S1, the TOC contents of 45 sludge samples varied from $7.05 \%$ to $45.0 \%$. The Spearman's coefficients of the concentrations of antibiotics and TOC of the sludge are present in Table 3. Significant correlation between TOC and total concentrations of antibiotics was found in these samples $(R=0.481, P<0.01)$, suggesting that antibiotics in sludge were significantly dependent on the sludge organic content. This may be related to their high potential to bind with organic matter in sewage sludge. Since the antibiotic concentrations in sludge increased with the increasing TOC contents, it can be assumed that TOC could affect the sludge adsorption capability to the antibiotics to some extent.

\subsubsection{Treatment capacity, processing volume, and serving population}

As the main design and operating parameters of WWTPs, treatment capacity, processing volume, and serving population were investigated to assess the pollutants of sewage sludge. This study showed that total concentrations of antibiotics have no significant relationships with the individual parameters $(p>0.05)$. Similar results were also found in previous studies that the levels of targeted analytes, such as short chain chlorinated paraffins, and benzotriazole UV stabilizers, were not related to these WWTP characteristics (Ruan et al., 2012; Zeng et al., 2012). However, significant correlation between the total concentrations of antibiotics and the ratio of processing volume to serving population was found in this study $(R=0.333, P<0.05)$ (Table 3$)$. This provides a general indication that the levels of antibiotics in sludge tend to be higher in those WWTPs that have higher daily loading per capita $\left(\mathrm{m}^{3}\right.$ per person and day). It should be noted that no such relationships were found in other studies. This may be explained by that the ratio of processing volume to serving population could factually reflect the actual working conditions of the studied WWTPs. Regarding information on such factors is rather scarce, the relation between the levels of antibiotics and these factors needs further investigations.

\subsubsection{Treatment technique}

Due to their reasonable operating and maintenance costs, wastewater treatment systems that use activated sludge processes have been employed extensively throughout the world. A previous study has shown that concentrations of antibiotics in influents and effluents of WWTP vary significantly depending on the types of wastewater treatment technique ( $\mathrm{Yu}$ and $\mathrm{Chu}, 2009$ ). Table S1 summarizes the four main treatment techniques of the investigated WWTPs, which were mainly grouped into oxidation ditch (OD), sequencing batch reactor (SBR), anoxic/oxic (AO), and anaerobic/anoxic/oxic (AAO) activated sludge processes. Principal component analysis (PCA) was performed to assess the characteristics of antibiotics in sewage sludge of WWTPs with different treatment techniques. Six quinolones (NOR, CIP, ENR, FLE, OFL and LOM), three sulfonamides (SMX, SPD and SDZ), and three macrolides (SPI, ROX and ERY), whose detectable rates were over $60 \%$ and mean concentrations were above $1 \mu \mathrm{g} / \mathrm{kg}$, were selected in this analysis. The varimax rotation reduced all variables to three principal components (PCs) with eigenvalues greater than 1 , which represent $70.06 \%$ of the cumulative variances. Figs. 3 and 4 
Table 3

Pearson's correlation matrix for the concentrations of target antibiotics with parameters of 45 WWTPs and TOC in the sludge.

\begin{tabular}{|c|c|c|c|c|c|c|c|c|}
\hline \multirow[t]{2}{*}{ Parameters } & \multicolumn{2}{|l|}{ QNs } & \multicolumn{2}{|l|}{ SAs } & \multicolumn{2}{|l|}{ MCs } & \multicolumn{2}{|l|}{ Total } \\
\hline & $\begin{array}{l}\text { Pearson } \\
\text { correlation }\end{array}$ & Sig. (2-tailed) & $\begin{array}{l}\text { Pearson } \\
\text { correlation }\end{array}$ & Sig. (2-tailed) & $\begin{array}{l}\text { Pearson } \\
\text { correlation }\end{array}$ & Sig. (2-tailed) & $\begin{array}{l}\text { Pearson } \\
\text { correlation }\end{array}$ & Sig. (2-tailed) \\
\hline Treatment capacity $\left(10^{4} \mathrm{~m}^{3} / \mathrm{d}\right)$ & -0.045 & 0.772 & 0.150 & 0.331 & -0.192 & 0.212 & -0.047 & 0.764 \\
\hline Processing volume $\left(10^{4} \mathrm{~m}^{3} / \mathrm{d}\right)$ & -0.027 & 0.864 & 0.127 & 0.410 & -0.169 & 0.272 & -0.028 & 0.856 \\
\hline Population $\left(10^{4}\right)$ & -0.068 & 0.659 & 0.039 & 0.802 & -0.208 & 0.176 & -0.070 & 0.649 \\
\hline Ratio $_{1}$ & 0.175 & 0.251 & $0.348^{*}$ & 0.019 & 0.052 & 0.735 & 0.175 & 0.249 \\
\hline Ratio $_{2}$ & $0.331^{*}$ & 0.026 & $0.393^{* *}$ & 0.008 & 0.206 & 0.174 & $0.333^{*}$ & 0.026 \\
\hline TOC (\%) & $0.480^{* *}$ & 0.001 & $0.661^{* *}$ & 0.000 & 0.170 & 0.269 & $0.481^{* *}$ & 0.001 \\
\hline
\end{tabular}

Ratio $_{1}=$ Treatment capacity/Population; Ratio $_{2}=$ Processing volume/Population .

** Correlation is significant at the 0.01 level (2-tailed).

* Correlation is significant at the 0.05 level (2-tailed).

illustrate the loading and score plots of the three PCs. As shown in the loading plot, PC1 accounted for $28.98 \%$ of the total variance and had strong positive loadings on NOR, SMX, SDZ, SPI, ROX, and ERY; PC2 accounted for as much as $23.61 \%$ of the total variance and had moderately positive loadings for CIP, OFL, LOM, and SPD; PC3 accounted for $17.47 \%$ of the total variance and had high correlation with ENR and FLE. The score plots of PCA in Fig. 4 were grouped by treatment techniques to visualize potential relationships. PCA results show that OD has higher loading values of PC1 and PC3 in the component plot, indicating higher concentrations of NOR, SMX, SDZ, SPI, ROX, ERY, ENR and FLE in these OD WWTPs, while SBR has higher loading values of PC2, suggesting higher level of CIP, OFL, LOM, and SPD in SBR WWTPs. In contrast, the other two treatment techniques, AAO and AO, show very low loading values of three PCs. This result indicated that low levels of these antibiotics were found in the two kinds of WWTPs.

The relation between treatment techniques and the total concentrations of antibiotics in sludge was also investigated. Fig. S3 showed that the average total concentrations of antibiotics treated by four activated sludge processes in the sludge samples were in the order of "OD $(15,089 \mu \mathrm{g} / \mathrm{kg})>$ SBR $(11,217 \mu \mathrm{g} / \mathrm{kg})>$ AAO $(7453 \mu \mathrm{g} / \mathrm{kg})>$ AO $(4510 \mu \mathrm{g} / \mathrm{kg})$ ). With the different operating parameters, the solid retention time (SRT) in the four types of treatment techniques was variable. In general, OD usually uses the extended aeration, which has a long SRT (20-40 days); Due to its big and batch reactor, SBR often operates with the SRT of 15-25 days; AAO usually operates with the SRT of 10-20 days; With the relatively simple process, AO possesses the relative short SRT (3-10 days). As an important parameter for activated sludge process design and operation (Batt et al., 2007; Clara et al., 2005), SRT may influence the levels of antibiotics in sludge.

It has been proved that longer SRT influences and improves the elimination of some pharmaceuticals by degradation processes during sewage treatment, but there is no clear conclusion as to whether SRT has an effect on the abiotic removal by sorption (Hyland et al., 2012). In the present study, the composition analysis indicated that the predominant antibiotics in sludge samples were quinolones, which accounted in average for $98.80 \%$ of the total antibiotics. Hence, the total concentrations of antibiotics in the sludge samples were mainly associated with the physiochemical properties and behaviors of quinolones. Many studies have shown that the dominant removal pathway for quinolones during wastewater treatment is sorption to sewage sludge rather than degradation. For example, approximately $80 \%$ of the total mass of both NOR and CIP sorbed to particles in the raw sewage water (Lindberg et al., 2006). In addition, it is known that quinolones have a high tendency for sorption to sludge, whose sorption coefficients are very high (Speltini et al., 2011). Thus, it was likely that quinolones would continually absorb onto the sludge during long contact time when biodegradative removal was not significant. Thus, longer SRT might cause the sludge to accumulate more quinolone antibiotics in wastewater. This study showed that treatment techniques for WWTP with different SRTs have a significant impact on antibiotics levels in sludge, consistent with the report by Schaar et al. (2010).
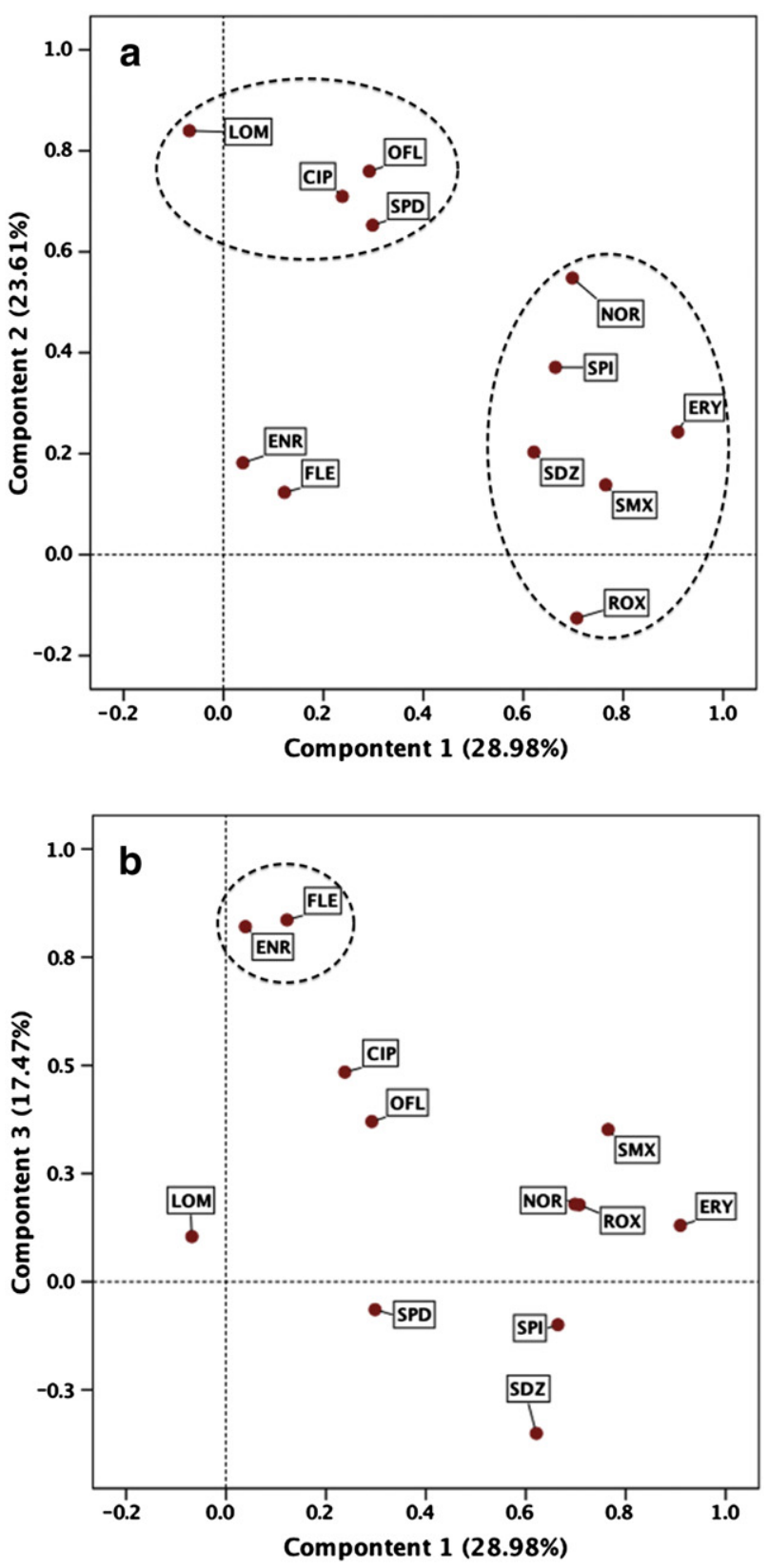

Fig. 3. The loading plots of PCA by the database of antibiotics in sludge in China 

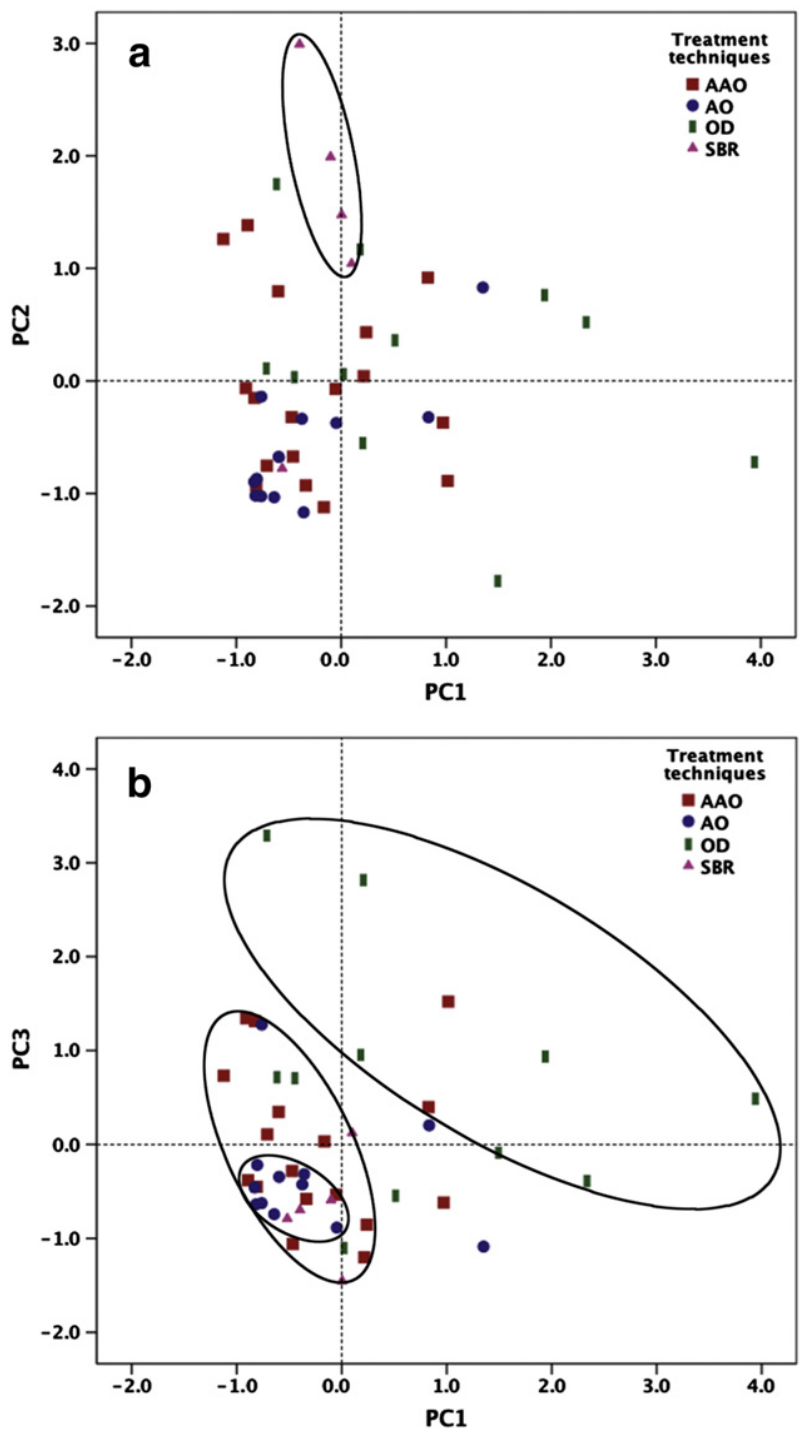

Fig. 4. The score plots of PCA by the database of antibiotics with different treatment techniques from the 45 WWTPs. a: PC1 vs PC2; b: PC1 vs PC3.

\section{Conclusions}

In the present work, a total of 18 antibiotics, including seven quinolones, six sulfonamides, and five macrolides, were detected in all sewage sludge samples collected from 45 WWTPs in 23 cities in China. The sludge samples from different WWTPs showed very similar composition profiles of antibiotics, indicating their universal usages and extensive pollution in China. Compared to previous studies, the levels of quinolones in this study were relatively high, while the concentrations of macrolides and sulfonamides were lower than or similar to those of other cities. This study found that the level of antibiotics in sewage sludge was associated with composition of the sewage, sludge organic content, the ratio of processing volume to serving population, and treatment techniques of the studied WWTPs. The risk of antibiotics in sludge needs further investigations, and the threat of these antibiotics in sludge should be of concern.

\section{Acknowledgments}

This work was supported by the National Natural Science Foundation of China (Nos. 20837003 and 20890111) and the National Basic Research Program of China (2009CB421605).

\section{Appendix A. Supplementary data}

Supplementary data to this article can be found online at http:// dx.doi.org/10.1016/j.scitotenv.2012.12.050.

\section{References}

Al-Rifai JH, Khabbaz H, Schafer AI. Removal of pharmaceuticals and endocrine disrupting compounds in a water recycling process using reverse osmosis systems. Sep Purif Technol 2011;77:60-7.

Baquero F, Martínez J-L, Cantón R. Antibiotics and antibiotic resistance in water environments. Curr Opin Biotechnol 2008;19:260-5.

Batt AL, Kim S, Aga DS. Comparison of the occurrence of antibiotics in four full-scale wastewater treatment plants with varying designs and operations. Chemosphere 2007; 68: 428-35.

Beausse J. Selected drugs in solid matrices: a review of environmental determination, occurrence and properties of principal substances. TrAC Trends Anal Chem 2004;23:753-61.

Bendz D, Paxéus NA, Ginn TR, Loge FJ. Occurrence and fate of pharmaceutically active compounds in the environment, a case study: Höje River in Sweden. J Hazard Mater 2005;122:195-204.

Carballa M, Omil F, Lema JM, Llompart M, Garcia C, Rodriguez I, et al. Behaviour of pharmaceuticals and personal care products in a sewage treatment plant of northwest Spain. Water Sci Technol 2005;52:29-35.

Chang X, Meyer MT, Liu X, Zhao Q, Chen H, Chen J-a, et al. Determination of antibiotics in sewage from hospitals, nursery and slaughter house, wastewater treatment plant and source water in Chongqing region of Three Gorge Reservoir in China. Environ Pollut 2010;158:1444-50.

Clara M, Strenn B, Gans O, Martinez E, Kreuzinger N, Kroiss H. Removal of selected pharmaceuticals, fragrances and endocrine disrupting compounds in a membrane bioreactor and conventional wastewater treatment plants. Water Res 2005;39: 4797-807.

Cruz Moreno-Bondi M, Dolores Marazuela M, Herranz S, Rodriguez E. An overview of sample preparation procedures for LC-MS multiclass antibiotic determination in environmental and food samples. Anal Bioanal Chem 2009;395:921-46.

Díaz-Cruz MS, García-Galán MJ, Guerra P, Jelic A, Postigo C, Eljarrat E, et al. Analysis of selected emerging contaminants in sewage sludge. TrAC Trends Anal Chem 2009;28:1263-75

Ellis J. Pharmaceutical and personal care products (PPCPs) in urban receiving waters. Environ Pollut 2006;144:184-9.

EPA. Method 1694: pharmaceuticals and personal care products in water, soil, sediment, and biosolids by HPLC/MS/MS. Available online:http://www.caslab.com/ EPA-Methods/PDF/1694.pdf 2007.

Escher BI, Baumgartner R, Koller M, Treyer K, Lienert J, McArdell CS. Environmental toxicology and risk assessment of pharmaceuticals from hospital wastewater. Water Res 2011;45:75-92.

Gao L, Shi Y, Li W, Niu H, Liu J, Cai Y. Occurrence of antibiotics in eight sewage treatment plants in Beijing, China. Chemosphere 2012;86:665-71.

Göbel A, Thomsen A, McArdell CS, Joss A, Giger W. Occurrence and sorption behavior of sulfonamides, macrolides, and trimethoprim in activated sludge treatment. Environ Sci Technol 2005;39:3981-9.

Gulkowska A, Leung HW, So MK, Taniyasu S, Yamashita N, Yeung LWY, et al. Removal of antibiotics from wastewater by sewage treatment facilities in Hong Kong and Shenzhen, China. Water Res 2008;42:395-403.

Hörsing M, Ledin A, Grabic R, Fick J, Tysklind M, JlC Jansen, et al. Determination of sorption of seventy-five pharmaceuticals in sewage sludge. Water Res 2011;45:4470-82.

Hyland KC, Dickenson ER, Drewes JE, Higgins CP. Sorption of ionized and neutral emerging trace organic compounds onto activated sludge from different wastewater treatment configurations. Water Res 2012;46:1958-68.

Jelić A, Petrović M, Barceló D. Multi-residue method for trace level determination of pharmaceuticals in solid samples using pressurized liquid extraction followed by liquid chromatography/quadrupole-linear ion trap mass spectrometry. Talanta 2009;80:363-71.

Jelic A, Gros M, Ginebreda A, Cespedes-Sánchez R, Ventura F, Petrovic M, et al. Occurrence, partition and removal of pharmaceuticals in sewage water and sludge during wastewater treatment. Water Res 2011;45:1165-76.

Jia A, Wan Y, Xiao Y, Hu J. Occurrence and fate of quinolone and fluoroquinolone antibiotics in a municipal sewage treatment plant. Water Res 2012;46:387-94.

Karthikeyan KG, Meyer MT. Occurrence of antibiotics in wastewater treatment facilities in Wisconsin, USA. Sci Total Environ 2006;361:196-207.

Kinney CA, Furlong ET, Zaugg SD, Burkhardt MR, Werner SL, Cahill JD, et al. Survey of organic wastewater contaminants in biosolids destined for land application. Environ Sci Technol 2006;40:7207-15.

Kümmerer K. Antibiotics in the aquatic environment-a review-part I. Chemosphere 2009;75:417-34.

Li W, Shi Y, Gao L, Liu J, Cai Y. Occurrence of antibiotics in water, sediments, aquatic plants, and animals from Baiyangdian Lake in North China. Chemosphere 2012;89:1307-15

Lillenberg M, Yurchenko S, Kipper K, Herodes K, Pihl V, Sepp K, et al. Simultaneous determination of fluoroquinolones, sulfonamides and tetracyclines in sewage sludge by pressurized liquid extraction and liquid chromatography electrospray ionization-mass spectrometry. J Chromatogr A 2009;1216:5949-54.

Lindberg RH, Olofsson U, Rendahl P, Johansson MI, Tysklind M, Andersson BAV. Behavior of fluoroquinolones and trimethoprim during mechanical, chemical, and active 
sludge treatment of sewage water and digestion of sludge. Environ Sci Technol 2006;40:1042-8

Maeng SK, Sharma SK, Lekkerkerker-Teunissen K, Amy GL. Occurrence and fate of bulk organic matter and pharmaceutically active compounds in managed aquifer recharge: a review. Water Res 2011;45:3015-33.

Malintan N, Mohd M. Determination of sulfonamides in selected Malaysian swine wastewater by high-performance liquid chromatography. J Chromatogr A 2006;1127:154-60.

Nieto A, Borrull F, Pocurull E, Marce RM. Occurrence of pharmaceuticals and hormones in sewage sludge. Environ Toxicol Chem 2010;29:1484-9.

Okuda T, Yamashita N, Tanaka H, Matsukawa H, Tanabe K. Development of extraction method of pharmaceuticals and their occurrences found in Japanese wastewater treatment plants. Environ Int 2009;35:815-20.

Peng X, Zhang K, Tang C, Huang Q Yu Y, Cui J. Distribution pattern, behavior, and fate of antibacterials in urban aquatic environments in South China. J Environ Monit 2011;13:446-54.

Pomati F, Netting AG, Calamari D, Neilan BA. Effects of erythromycin, tetracycline and ibuprofen on the growth of Synechocystis sp. and Lemna minor. Aquat Toxicol 2004;67:387-96.

Radjenović J, Jelić A, Petrović M, Barceló D. Determination of pharmaceuticals in sewage sludge by pressurized liquid extraction (PLE) coupled to liquid chromatographytandem mass spectrometry (LC-MS/MS). Anal Bioanal Chem 2009;393:1685-95.

Robinson AA, Belden JB, Lydy MJ. Toxicity of fluoroquinolone antibiotics to aquatic organisms. Environ Toxicol Chem 2005;24:423-30.

Ruan T, Liu R, Fu Q, Wang T, Wang Y, Song S, et al. Concentrations and composition profiles of benzotriazole UV stabilizers in municipal sewage sludge in China. Environ Sci Technol 2012:46:2071-9.

Sapkota A, Sapkota AR, Kucharski M, Burke J, McKenzie S, Walker P, et al. Aquaculture practices and potential human health risks: current knowledge and future priorities. Environ Int 2008;34:1215-26.

Schaar H, Clara M, Gans O, Kreuzinger N. Micropollutant removal during biological wastewater treatment and a subsequent ozonation step. Environ Pollut 2010;158:1399-404

Speltini A, Sturini M, Maraschi F, Profumo A, Albini A. Analytical methods for the determination of fluoroquinolones in solid environmental matrices. TrAC Trends Ana Chem 2011;30:1337-50.
Tamtam F, Mercier F, Le Bot B, Eurin J, Tuc Dinh $\mathrm{Q}$ Clément $\mathrm{M}$, et al. Occurrence and fate of antibiotics in the Seine River in various hydrological conditions. Sci Total Environ 2008;393:84-95.

Wu C, Spongberg AL, Witter JD, Fang M, Czajkowski KP. Uptake of pharmaceutical and personal care products by soybean plants from soils applied with biosolids and irrigated with contaminated water. Environ Sci Technol 2010;44:6157-61.

Xu W, Zhang G, Li X, Zou S, Li P, Hu Z, et al. Occurrence and elimination of antibiotics at four sewage treatment plants in the Pearl River Delta (PRD), South China. Water Res 2007;41:4526-34.

Yang S, Lin C, Wu C, Ng K, Lin AY, Hong PA. Fate of sulfonamide antibiotics in contact with activated sludge-sorption and biodegradation. Water Res 2012:46:1301-8.

Yu C, Chu K. Occurrence of pharmaceuticals and personal care products along the West Prong Little Pigeon River in east Tennessee, USA. Chemosphere 2009;75:1281-6.

Zeng L, Wang T, Ruan T, Liu Q, Wang Y, Jiang G. Levels and distribution patterns of short chain chlorinated paraffins in sewage sludge of wastewater treatment plants in China. Environ Pollut 2012;160:88-94.

Zhang D, Lin L, Luo Z, Yan C, Zhang X. Occurrence of selected antibiotics in Jiulongjiang River in various seasons, South China. J Environ Monit 2011;13:1953-60.

Zhou H, Huang X, Gao M, Wang X, Wen XH. Distribution and elimination of polycyclic musks in three sewage treatment plants of Beijing, China. J Environ Sci (China) 2009;21:561-7.

Zhou L, Ying G, Zhao J, Yang J, Wang L, Yang B, et al. Trends in the occurrence of human and veterinary antibiotics in the sediments of the Yellow River, Hai River and Liao River in northern China. Environ Pollut 2011;159:1877-85.

Zorita S, Mårtensson L, Mathiasson L. Occurrence and removal of pharmaceuticals in a municipal sewage treatment system in the south of Sweden. Sci Total Environ 2009;407:2760-70

Zou B, Wang H. Present situation and progress of sewage sludge treatment and disposal. Value Eng 2012;13:30-1.

Zuccato E, Castiglioni S, Bagnati R, Melis M, Fanelli R. Source, occurrence and fate of antibiotics in the Italian aquatic environment. J Hazard Mater 2010;179:1042-8. 